\title{
Automation in Agriculture to Optimize Utilization of Water and Crop Monitoring using IOT
}

\author{
M. A. Wakchaure \\ Professor \\ Department of Computer Engineering \\ Amrutvahini College of Engineering \\ Sangamner
}

\author{
Nishant L. Kale \\ Computer Engineering \\ AVCOE, Sangamner
}

\author{
Pradeep G. \\ Gawade \\ Computer Engineering \\ AVCOE, Sangamner
}

\author{
Lakhan V. Gangule \\ Computer Engineering \\ AVCOE, Sangamner
}

\author{
Laxman D. Chate \\ Computer Engineering \\ AVCOE, Sangamner
}

\begin{abstract}
In India Agriculture plays very important role in the economy. As contribution of agriculture to total domestic product is declining in these days, it is our responsibility to increase crop productivity with efficient and effective water usage and energy consumption. It provides a solution for measurement of environmental parameters like rain, temperature, moisture, and water level. In order to increase agriculture production the basic idea is smart agriculture which can be achieved through smart irrigation. It is need of hour to implement to implements several smart techniques using smart control system. The level of agricultural activities can be improved so as to gain sustainable development so that the needs of future generation can be fulfilled by acquiring smart modes of production and consumption.
\end{abstract}

\section{Keywords}

Internet of things, Wireless sensor network, Agriculture Automation, Irrigation, Arduino, Sensors.

\section{INTRODUCTION}

The Indian economy is basically an agriculture society. Despite economic development and industrialization, agriculture is the backbone of the Indian System. Agriculture uses most of available fresh water resources and use of fresh water resources will continue to be increases rapidly, due to population growth and increased food demand. This paper presents implementation of agricultural automation using WEB and GSM technologies. This project was developed to harvest water use for agriculture. Here we are using different sensors which are mounted at root zones of the field. By using the GSM technology status of the sensors will be dispatch to control unit. GSM is used for sending the message and GPRS is used for displaying the values in the webpage.

There is need forimprovement on the existing or old forms ofirrigation. An automated irrigation system needsto be developed to optimize water use foragricultural crops [3]. An intelligent automaticirrigation system has to have all the componentsthat autonomously monitor and control the level of water available to the plants without anyfailure or human intervention [4].

The process of maintaining the soil moistureis deployed in this project work. Using this method, the amount of water supplied to theagricultural items is minimized and itslashescrop production cost. Agriculture process, as per [10] are based onthe following; the experience of user,the soil nature and climateconditions. A best way to maintain theenvironmental conditions and effective usageof water to prevent wastage is by the use ofsensor network.

\section{EXISTING SYSTEM}

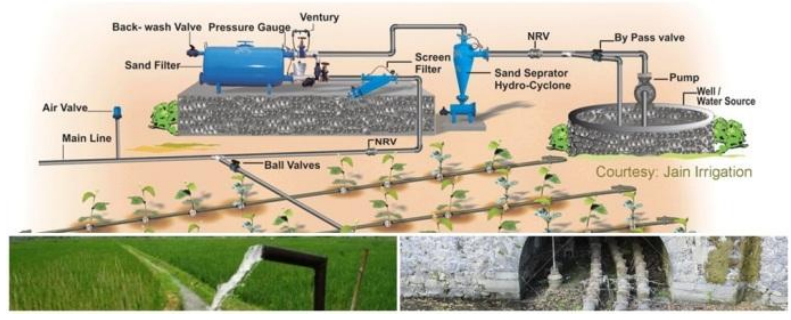

Fig.1 An overview of existing Irrigation system

\section{PROPOSED SYSTEM}

In this section we are going to scale the agriculture system to improve the performance of the system. We nomenclature this system as Automation in Agriculture using IOT.

\subsection{An overview of proposed system}

The Fig. 2 shows the use case of the Smart Agriculture system. Automation system has been developed to give the automatic supply of suitable water from a tank to farm . Main aim of this work is to see how human control could be removed from agriculture and also to reduce the use of water in the process of automation [2].

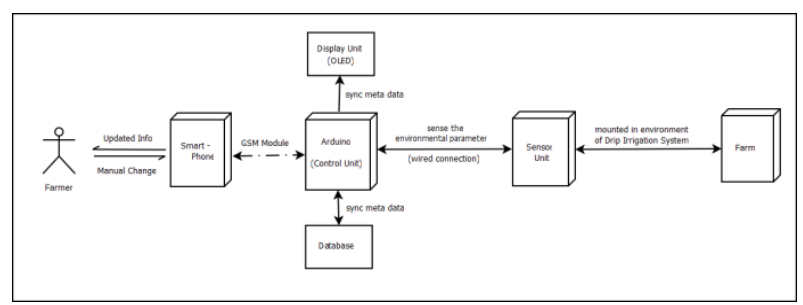

Fig.2. Use Case for Automatic Irrigation System

\subsection{Architecture of Automation in Agriculture System:}

Automation of the farm irrigation system using a Wireless sensor network. The system provides application interface to the user so that they can control and monitor the system from to the remote place. Micro-Controller (328) is used as a controller board which is designed based on the 
microcontroller (328) architecture. Micro-Controller(328) makes the communication with all distributed sensor nodes placed in the farm through wired as well as wireless mode and also act as a co-ordinating node in the wireless sensor network. The goal of coordinating node is to collect the parameters like soil moisture, water level ,temperature, LDR remotely [3].

Soil moisture sensor gives value to micro-controller which can alert farmers about irregular conditions and atmosphere to give water after specific time period.The water level sensors can sense the level of water providing significant saving of water and making appropriate use of it. Temperature sensor senses the surrounding temperature and taking parameters into consideration decisions regarding temperature fluctuations if at all necessary are taken. Also LDR is used to detect light intensity and necessary changes in the light intensity are made.

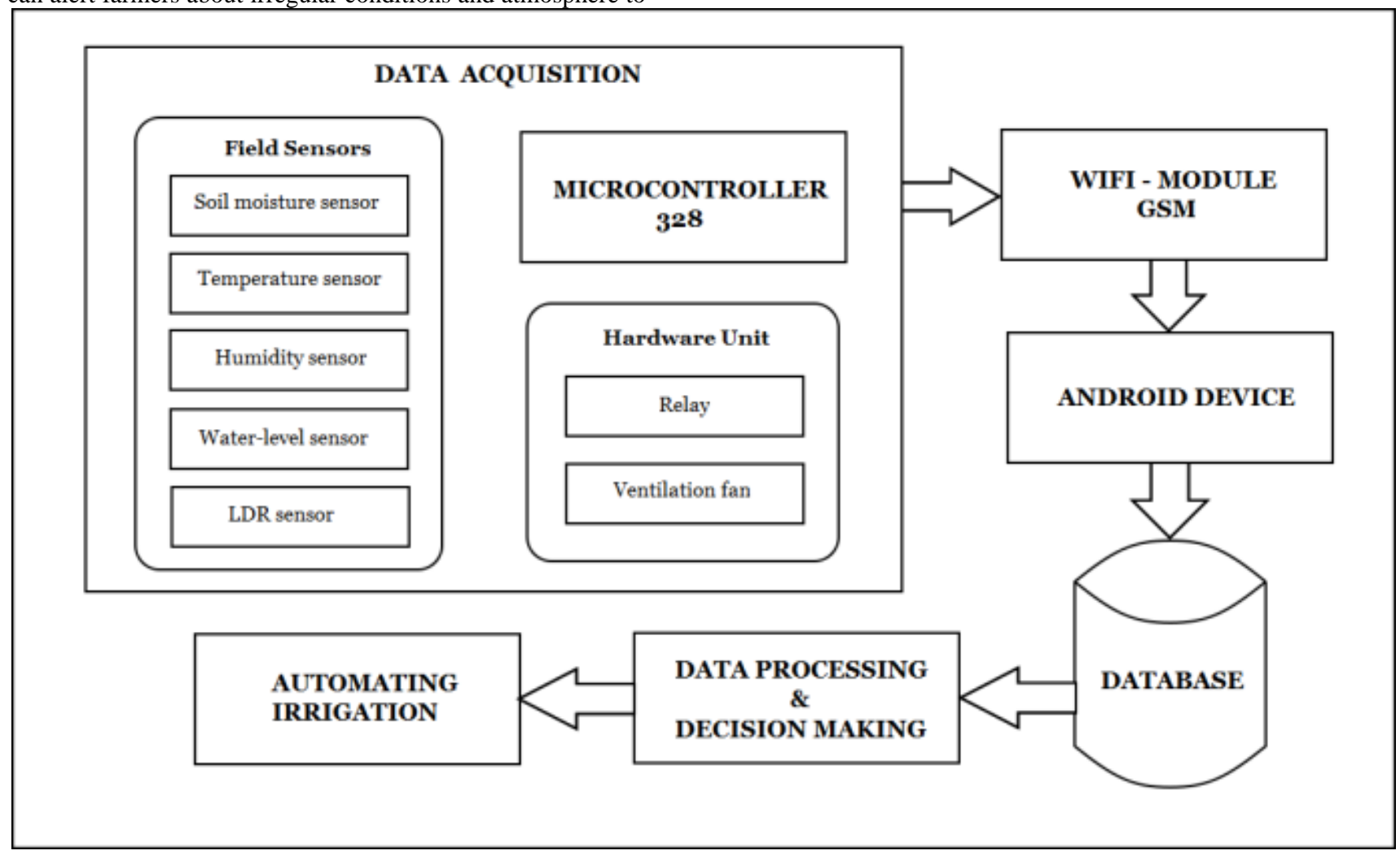

Fig.3 Architecture for Automatic Irrigation System

Natural resources namely solar energy and wind energy also plays an equally important role in smart irrigation phenomena. Moreover, in poly-house farming smart sprinkler as well as drip irrigation techniques are strongly recommended [7].

Drip irrigation has the potential to save water and nutrients on a large scale also it help farmers to manage water scarcity, save resources and enhance productivity. At times in order to control excessive growth of weeds necessary pesticides and fertilizers must be sprinkled in smart way by using smart sensor.

\section{TECHNOLOGY STACK}

Different sensors such as level sensor, temperature sensor, moisture sensor will be used. Micro-controller-328 kit is used for processing the data which is gathered from sensor. All sensors are connected to microcontroller-328 kit as source of input from farm. When farmer mounts above sensors to his farm, sensors senses various environmental parameters such as soil moisture, temperature, level of water, etc. Once the data from sensors is received by microcontroller-328, it sends to the database (JSON database) through internet.Automation in Agriculture using IOT [1].

\subsection{Soil Moisture Sensor}

Soil moisture samples are important for agricultural automation to help farmers to manage their agriculture systems more efficiently with easiest way. In this project we use soil sensor. It is used for checking the soil condition. her it is in wet condition or is in dry condition [3].

The Fig.4 Shows soil moisture sensor.

This Sensor is used to check the moisture level of Soil. When tank water level is less than $10 \%$ at that time motor remains OFF and GSM module sends notification on the android application.

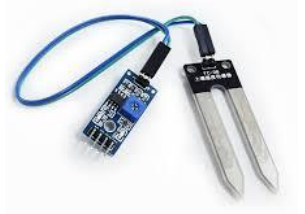

Fig.4 Soil Moisture sensor 


\subsection{Tempreture and Humidity Sensor}

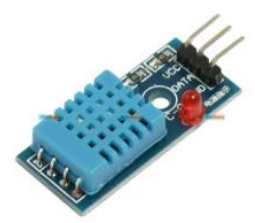

Fig.5 Humidity sennsor

In this project humidity sensor is used. Humidity is the amount of water vapor in the air.The Fig.5 Shows soil moisture sensor.

This Sensor is used to check the moisture level of Soil. When tank water level is less than $10 \%$ at at that time motor remains OFF and GSM module sends notification on the android application.

\subsection{Water Level Sensor (Ultrasonic Sensor)}

Ultrasonic sensor is used to measure the water level in tank. Depending on the level of water in tank motor is ON/OFF. If the level of water is in below the threshold level i.e. below the low level the motor is in ON condition. If the water level sensor is in medium or high levels the motor is in OFF condition.

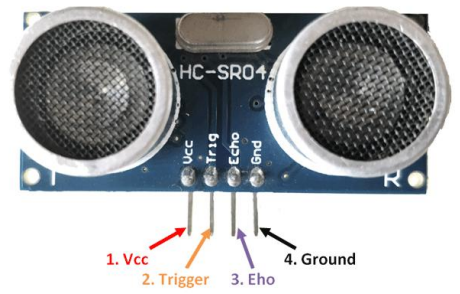

Fig.6: Water Level sennsor

The Fig.6 Shows soil moisture sensor moisture sensor.

\subsection{IR Sensor}

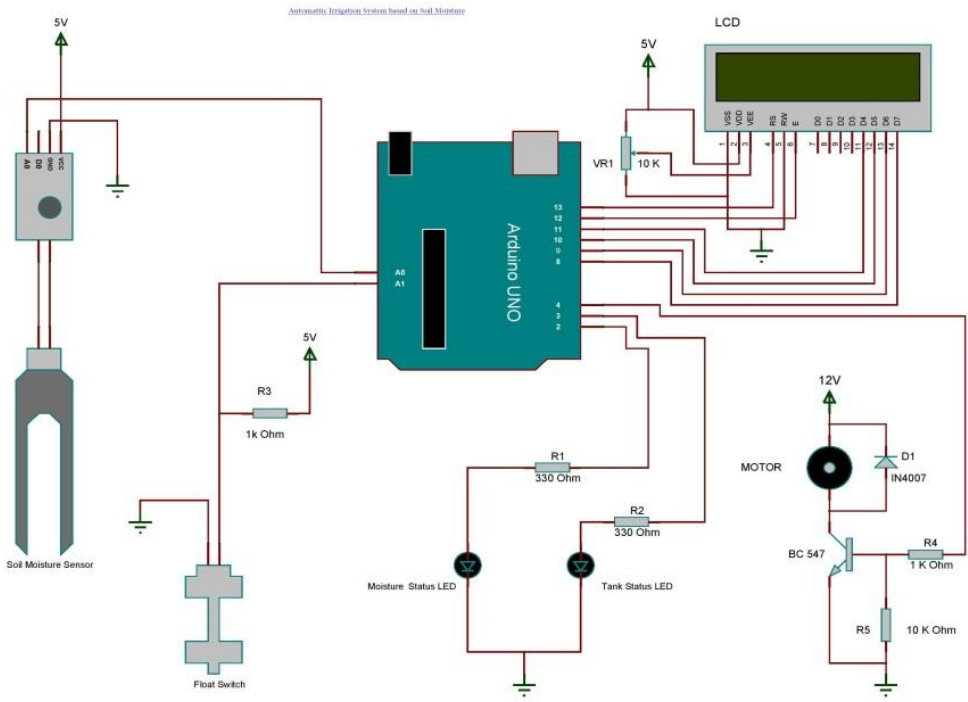

Fig.9: Sensing and Control circuits

An infrared sensor is an electronic component that emits and/or detects infrared radiation in order to sense some obstacle of its surroundings. Infrared sensors can detect the object, as well as detect motion. The below Fig.7.Shows IR sensor.

\subsection{OLED Display}

OLED display is an electronic component. Display is very basic module and is very commonly used invarious devices and circuits.In this project the display is used for displaying the sensor output value.

The below Fig.8 Shows OLED Display.

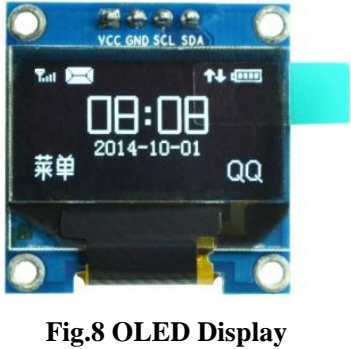

5. WORKING OF PROPOSED SYSTEM

Implementation of agricultural automation system via cloud and GSM technology consists of sensor unit and field information [6]. Mainly this project is used for decreasing human effort and for harvest water usage in the field of agriculture.

In our system we use the following sensors:

- Temperature sensor:It sens the temperature changes. 
- Soil sensor: It checks the soil condition. Whether is wet or dry.

- Humidity sensor :It sense the humidity present in the surroundings environment.

- IR sensor: It is used for finding the intruder.

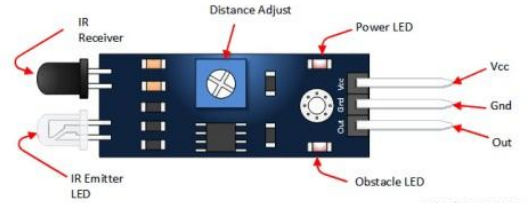

- Ultrasonic sensor : It displays water levels whether water is in low or medium or in high levels.

When farmer applies above sensors to their farm, sensors sense various parameters of farm environment such as temperature, level of water, soil moistureetc. This sensed data is collected by arduino micro controller [8].

The arduino kit is implemented with wi-fi module so that it can be connected to internet. once data from sensors is arrived to arduino, it sends it to the database through internet. In this we are using json database where all data is stored.

By using a system GUI user is able to access all the parameters regarding his farm remotely due to database since data is access through web url from the database.

The OLED displays as "WELCOME TO THE PROJECT". And it displays temperature, water level, humidity, soil moisture values. First we check the condition of soil in the farm. When moisture value is less than the threshold value then the motor gets started automatically but at same time water level is also checked. When there will no water in external tank then motor is off. There are different conditions for the automation of the agriculture system [4]. It depends on the sensor values and these conditions are given in following Table.1 For each and every time these values are displayed on the OLED display. By using GSM technology value are transferred from field sensor unit to cloud and then cloud to application. The status of updated result is send to webpage by using GSM technology [10].

Table.1 Agricultural Automation Conditions

\begin{tabular}{|r|l|l|l|}
\hline \multicolumn{1}{|r|}{ Case } & Soil Moisture & $\begin{array}{l}\text { Water } \\
\text { Level }\end{array}$ & $\begin{array}{l}\text { Motor } \\
\text { Status }\end{array}$ \\
\hline 1. & DRY & FULL & ON \\
\hline 2. & WET & FULL & OFF \\
\hline 3. & DRY & MEDIUM & ON \\
\hline 4. & WET & MEDIUM & OFF \\
\hline 5. & DRY & LOW & ON \\
\hline 6. & WET & LOW & OFF \\
\hline 7. & DRY & NULL & OFF \\
\hline 8. & WET & NULL & OFF \\
\hline
\end{tabular}

\section{RESULT}

6.1 OLED Display Output results:

The Output is displayed on OLED Display, also the alerts and warning messages which will be send on Android and Web portal will also be displayed on Screen which will be present at home as well farm.

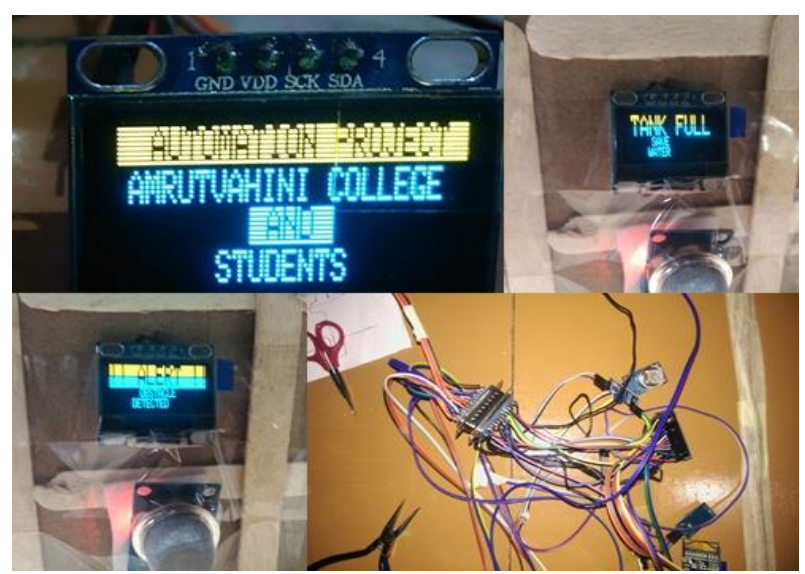

OLED output results are shown as in Fig.10 above.

\subsection{Output of Working System Module}
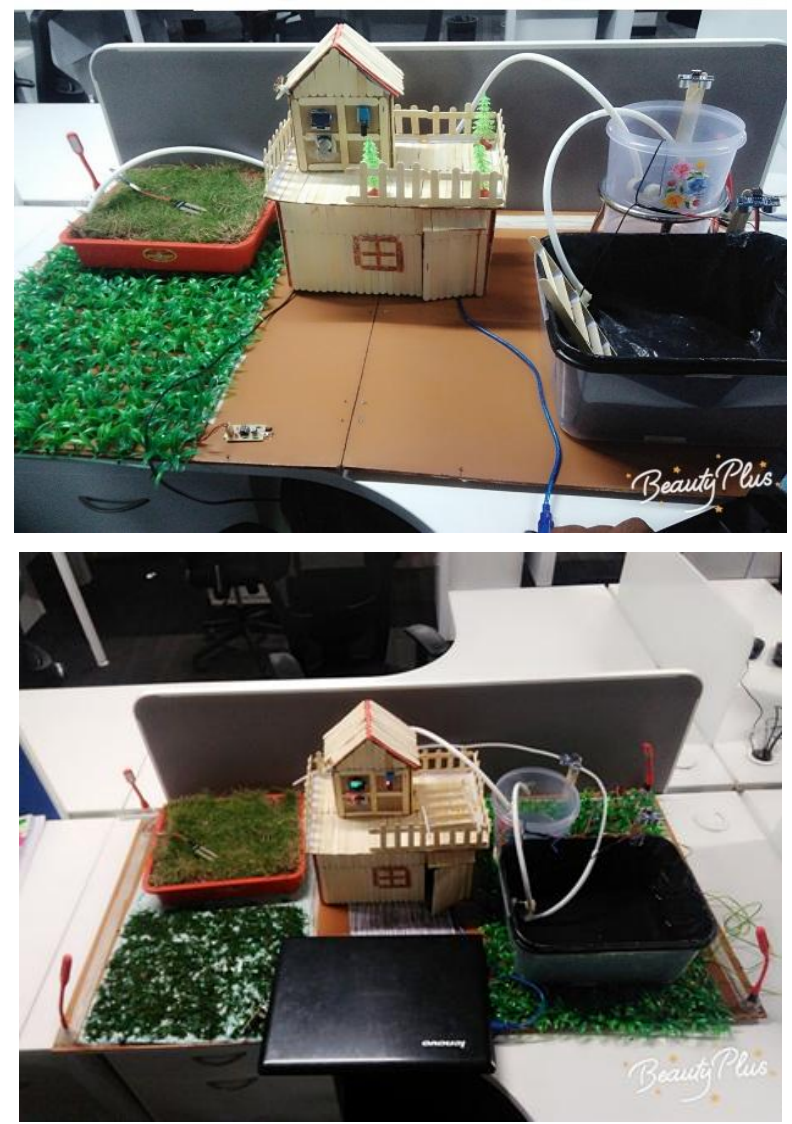

Fig.11 Working System Module 


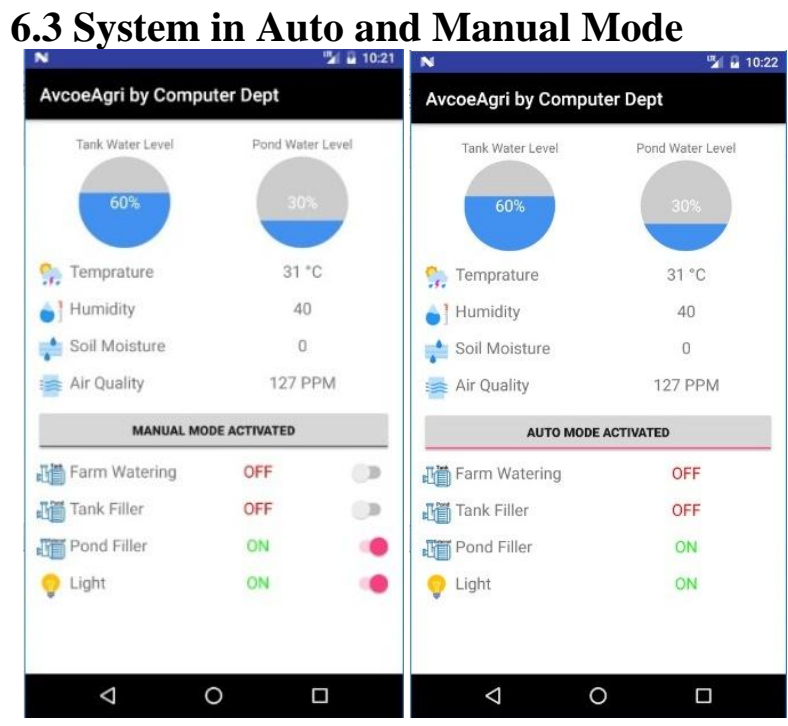

Fig.12 System in Auto and Manual Mode

\subsection{Real Time Background Notification}

10:28 PM - Tue, May 8
AvriAvcoe Alert
Gate opened
N Android System
USB debugging connected
Tap to disable USB debugging.

Fig.13 System in Auto and Manual Mode

\section{CONCLUSION AND FUTURE WORK}

Automatic agriculture system has been designed. The prototype of theproject worked according to specification. The system components areeasily available, affordable and reliable.

The system helps toeliminate the stress of farmer and agriculture equipment control while at the same time conserving the available water resources. Improving agriculture efficiency can contribute greatly to decreasing production costs of agricultural products, thereby making the agriculture industry to be more competitive. The agriculture system was tested on three types of soil and after the result analysis sandy soils require less water than moisturised soils and clay soils require the most water for agriculture [7].

For future work on this system, we recommend that for a large scale implementation a more powerful water pump can be used. Arduinocontrols different agriculture equipment. Awireless sensor and GPRS (General Packet Radio Service) based automated agriculture system canalso be placed, which according to [3, 4], will help monitor the soil moisture and tocontrol the application of water to the agricultural products thereby saving water.

\section{REFERENCES}

[1] ArindamGiri,SubrataDutta,SarmisthaNeogy, Enabling Agricultural Automation to Optimize Utilization of Water, Fertilizer and Insecticides by implementingInternet of Things (IoT),2016 IEEE Haldia India Section International Conferenceon Electrical, Computer and Electronics Engineering (UPCON) Indian Instituteof Technology (Banaras Hindu University) Varanasi, India, Dec 9-11, 2016

[2] Kabilan N 1 ,PG Scholar,Dr. M. SenthamilSelvi 2 ,Surveillance and Steeringof Irrigation System in Cloud using Wireless Sensor Network and Wi-Fi Module, FIFTH INTERNATIONAL CONFERENCE ON RECENT TRENDS ININFORMATION TECHNOLOGY,2016

[3] Rajalakshmi.P,Mrs.S.DeviMahalakshmiIOT Based CropField Monitoring And Irrigation Automation, 2016 IEEE.

[4] Dr. D.K. Sreekantha, Kavya.A.MAgricultural Crop Monitoring using IOTAStudy, 11th International Conference on Intelligent Systems and Control(ISCO)2017 IEEE.K

[5] Pavithra D.S, Srinath M.S "GSM based automatic irrigation control system for efficient use of resources and crop planning by using an Android mobile" IOSR Journal of Mechanical and Civil Engineering Volume 11, Issue 4 Ver.1 July-August 2014 p. 49-55

[6] AbhinavRajpal, Sumit Jain, NisthaKhare and Anil Kumar Shukla "Microcontroller-based Automatic Irrigation System with Moisture Sensor" Proceedings of the International Conference on Science and Engineering (ICSE 2011).

[7] JoaqunGutirrez, Juan Francisco Villa-Medina, Alejandra Nieto- Garibay, And Miguel ngelPorta-Gndara, "Automated Irrigation System Using A Wireless Sensor Network And GPRS Module", Ieee Transactions On Instrumentation And Measurement, Vol. 63, No. 1, January 2014.

[8] Vimal P, Priyanka.V, Rajyasree.M, Santhiyadevi P.T, Jagadeeshraja.M, SuthanthiraVanitha.N"A Novel Approach for Automatic Irrigation and Fertigation Using Embedded System," International Journal of VLSI and Embedded Systems-IjvesVol 05, Article 03257; March 2014.

[9] Sathiyabama P, Lakshmi Priya C, Ramesh Sm, Preethi B, Mohanaarasi M, "Embedded System Design For Irrigating Field With Different Crops Using Soil Moisture Sensor," International Journal Of Innovative Research In Computer And Communication Engineering Vol. 2, Issue 8, August 2014.

[10] S.MuhammadUmair, R. Usman,"Automation Of Irrigation System Using Ann Based Controller," International Journal Of Electrical Computer Sciences Ijecs-IjensVol: 10 No: 02.May2010.

[11] Dr. D. K. Sreekantha, Kavya.A.MAgricultural Crop Monitoring using IOTAStudy, 11th International Conference on Intelligent Systems and Control(ISCO)2017 IEEE.K

[12] J. M. Corchado, J. Bajo, D. I. Tapia, and A. Abraham, "Using heterogeneous wireless sensor networks in a telemonitoring system for healthcare," IEEE Trans. Inf. Technol. Biomed., vol. 14, no. 2, pp. 234-240, Mar. 2010. 
[13] G. X. Lee, K. S. Low, and T. Taher, "Unrestrained measurement of arm motion based on a wearable wireless sensor network," IEEE Trans. Instrum. Meas., vol. 59, no. 5, pp. 1309-1317, May 2010.

[14] D. M. Han and J.-H. Lim, "Smart home energy management system using IEEE 802.15.4 and ZigBee," IEEE Trans. Consum. Electron., vol. 56, no. 3, pp. 14031410, Aug. 2010.

[15] C. Gomez and J. Paradells, "Wireless home automation networks: A survey of architectures and technologies," IEEE Commun. Mag., vol. 48, no. 6, pp. 92-101, Jun. 2010.

[16] M. Bertocco, G. Gamba, A. Sona, and S. Vitturi, "Experimental characterization of wireless sensor networks for industrial applications," IEEE Trans. Instrum. Meas., vol. 57, no. 8, pp. 1537-1546, Aug. 2008.

[17] V. C. Gungor and G. P. Hancke, "Industrial wireless sensor networks: Challenges, design principles, and technical approaches," IEEE Trans. Ind. Electron., vol. 56, no. 10, pp. 4258-4265, Oct. 2009.

[18] L. Hou and N. W. Bergmann, "Novel industrial wireless sensor networks for machine condition monitoring and fault diagnosis," IEEE Trans. Instrum. Meas., vol. 61, no. 10, pp. 2787-2798, Oct. 2012.

[19] A. Carullo, S. Corbellini, M. Parvis, and A. Vallan, "A wireless sensor network for cold-chain monitoring," IEEE Trans. Instrum. Meas., vol. 58, no. 5, pp. 14051411, May 2009.

[20] Gutierrez J, Villa Medina J F, Nieto Garibay A, and Angel Porta Gandara M. Automated Irrigation System Using a Wireless Sensor Network and GPRS Module. IEEE Transactions on Instrumentation and Measurement 2014; 13(1): 166-176.
[21] Mohamed RawideanMohdKassim, Ibrahim Mat "Wireless Sensor Network in Precision Agriculture Application", Ministry of Science, Technology and Innovation Kuala Lumpur, IEEE2014.http://www.academia.edu/9144402/Wireless_Senso r_Netw ork_in_Precision_Agriculture_Application

[22] Prof.Dr. Sanjeev wagh "Monitoring and Detection of Agricultural Disease using Wireless Sensor Network "computer Scinece \& Engineering from the SRT Marathavada University, Nanded 3International Journal of Computer Applications (0975- 8887) Volume 87No.4, February 2014. http://research.ijcaonline.org/volume87/number4/pxc389 3573.pdf

[23] Dr. D.K. Sreekantha, Kavya.A.M Professor" Agricultural Crop Monitoring using IOT- A Study", Department of Computer International Journal of Engineering Science and Computing, March 20175221 http://ijesc.org/ Science and Engineering, NMAM Institute of Technology,Nitte, Karnataka, India, 2017 11th International Conference on Intelligent Systems and Control (ISCO),16 February 2017http: //ieeexplore.ieee.org/document/7855968/

[24] AnjumAwasthi, S.R.N Reddy, "Monitoring for precision agriculture using Wireless sensor network - a review," the Global Journal of Computer Science and Technology Networks, Web \& Security, vol. 13, issue 7, 2013. https://globaljournals.org /GJCST_Volume13/5Monitoring-for-Precision-Agriculture.pdf

[25] Tuan Dinh Le, DatHo Tan "Design and Deploy a Wireless Sensor Network for Precision Agriculture" Department of Computer Sciences, in IEEE Sensors Journal, Vol. 11, No. 1, pp. 45-55, 2011.http://ieeexplore.ieee.org/document/7302210/ 